\title{
Language Maintenance and Language Shift among Second Generation Tigrinya-speaking Eritrean Immigrants in Saudi Arabia
}

\author{
Hussein Ali Habtoor \\ Department of English, College of Education at Shabwah, Aden University, Yemen \\ Email: haahabtoor@yahoo.co.uk; haahabtoor@gmail.com
}

\begin{abstract}
This paper addresses the language maintenance and language shift among the young Tigrinyaspeaking Eritrean immigrants in Riyadh, Kingdom of Saudi Arabia. Sixty-four Tigrinya-speaking teenager immigrants in Riyadh participated in this study. Forty of them are females and twenty-four are males. These respondents are students enrolled in the Eritrean International School in Riyadh. The results reveal that respondents have a limited ability to understand, speak, read, write, and translate orally Tigrinya into Arabic and vice-versa. In comparing the level of their proficiency in both Tigrinya and Arabic, it is found that they have a lower proficiency in Tigrinya than in Arabic. The use of Tigrinya is seemingly decreasing and the use of Arabic is increasing. Therefore, there is evidence from this study that second-generation Tigrinya teenagers' proficiency is shifting toward Arabic rather than maintaining the native language.
\end{abstract}

Index Terms - language maintenance, language shift, language contact, Eritrean immigrants

\section{INTRODUCTION}

This study focuses on language maintenance and language shift (LMLS) among the young Tigrinya-speaking Eritrean immigrants in Riyadh, Kingdom of Saudi Arabia. At the outset, it is very significant to have a brief underpinning milieu of Eritrea, the homeland of those immigrants, and its languages. Eritrea is located along the Red Sea, north of the horn of Africa. It is bordered by Djibouti and Ethiopia in the south and by Sudan in the west and north. Its total area is 124.320 square kilometres. TheUN estimates the population of Eritrea in 2010 at 5.224000. The Tigray and Tigre-speakers (such as the Mensa, the Marya, and others) constitute $80 \%$ of the population. The other seven groups are the Afar (Dankali), Bilen, Beni Amir (Beja), Kunama, Nera (Nara Baraya), Rasha'ida, andSaho'. As far as religion is concerned, nearly half of the Eritrean population is Sunni Muslim, and some 40 percent, Orthodox Christians. The reminder includes Eastern Rite and Roman Catholics, Protestants, smaller numbers of Seventh Day Adventists, and Jehova's Witnesses, and a few Baha'is².

The languages in Eritrea can be classified into three main categories according to the language family classification: Semitic language family, which includes Arabic, Tigrinya, Tigre, and Dahlik; Cushitic language family, which includes Afar, Beja, Bilen and Saho, and finally Nilo-Sahara language family which includes Kunama and Nara. Modern Standard Arabic, English and Tigrinya are the three official languages. Arabic and Tigrinya are the most widely used languages. Along with Italian, they are used in commercial and public businesses. English is also widely spoken and is the medium of instruction in middle and secondary schools and in higher education. Other languages spoken in Eritrea, according to Lewis (2009), are the immigrants languages: Central Kanuri, Hadrami Spoken Arabic(100,000) speakers, Hausa, Qimant, Sudanese Spoken Arabic $(100,000)$ speakers, Ta'izzi-Adeni Spoken Arabic(18,000).As noted earlier, Tigrinya is a member of the Southern Semitic language subfamily of the Afro-Asiatic family. It is the second largest member of the Ethiopian branch of the Semitic family of languages, and it constitutes together with Tigre the extinct Ge'ez (or classical Ethiopic) the northern subdivision (Appleyard 2006). According to the University of California at Los Angeles (UCLA) Language Project ${ }^{3}$ the number of speakers of Tigrinya are estimated at 4.5 million in both Eritrea and Ethiopia. It is spoken primarily in the Tigray province of Ethiopia and in the highlands and urban centres of Eretria. In Eritrea Tigrinya is spoken by approximately 1.2 million people, whereas approximately 3.2 million people in Ethiopia speak it.

Eritreans in Saudi Arabia

Eritrean communities are mainly settled in neighbouring countries in Africa and the Middle East, a marginal part of the diaspora is located in the west (Thiollet, 2007). Eritreans are hosted by the neighbouring countries like Sudan,

\footnotetext{
${ }^{1}$ Library of Congress - Federal Research Division, Country Profile: Eritrea, September 2005, p. 6 at http://memory.loc.gov/frd/cs/profiles/Eritrea.pdf Accessed on Feb. $5^{\text {th }} 2011$

2 ibid, p. 7

University of California at Los Angeles (UCLA Language

http://www.lmp.ucla.edu/Profile.aspx?LangID=18\&menu=004, Accessed on Feb. 62011

Material

Project):

language Profile

at
} 
Yemen and Saudi Arabia as either emigrants or refugees. At the end of 2004, nearly 120,000 Eritreans were refugees abroad, mostly in Sudan (UCLA) ${ }^{4}$. According to Thiollet $(2007,8)$, there are more than 100,000 Eritreans in the kingdom of Saudi Arabia. She also added that "most of the Eritreans entered Saudi Arabia without documents, with their refugee documents, or with a Haj or Umrah visa.”(p.8) Anyway, the Saudi Government facilitates the residential procedure for the Eritrean community in the country through immigration laws and they are granted residential permits and they work in different sectors in Saudi Arabia. Saudi Arabia gives a special financial and political support to the Eritreans as noted by Thiollet (2007) "The most efficient part of Saudi Arabia's support policy was to grant Eritreans quasi-asylum status in the 1970s and 1980s, and the tolerateration of Eritreans settlements in the country"(p. 8).

The Ministry of Labour in Riyadh counted 53,000 Eritrean workers in 2004, whereas the Eritrean embassy acknowledges the presence of around 100,000 of its citizens in the Kingdom. The Eritrean community is relatively a large community in Riyadh and there is another big Eritrean community in Jeddah and a smaller one in Jazan. The Eritreans in Riyadh are the subjects of this study. They work in several services in the Saudi capital. The Eritrean community has established its school in Al-Nasriah District, one of the busiest quarters of Riyadh. This school was established in 1995 by the effort of the Embassy and Eritrean Community to facilitate the obstacles, which their citizens were facing to get the best standard of education. ${ }^{5}$ The Eritrean community established this school to offer the children with an education equal to those living at home. This school began with 60 students at the nursery level to grade two, three teaching staff, one administrative staff and two rooms. In 2009, the school included about 1762 students from KG 1 to grade twelve (see table 1 below).

TABLE 1.

THE ERITREAN INTERNATIONAL SCHOOL STUDENTS' STATISTICS IN RIYADH CLASSIFIED BY GRADES AND SECTIONS, SCHOOL YEAR 2009.

\begin{tabular}{|l|l|l|l|l|l|l|l|l|l|}
\hline Section & A & B & C & D & E & F & G & H & Total \\
\hline KG1 & 23 & 27 & 28 & 27 & 24 & & & & 129 \\
\hline KG2 & 18 & 23 & 22 & 21 & 23 & 23 & 22 & 20 & 172 \\
\hline Grade 1 & 23 & 25 & 24 & 24 & 24 & 25 & & & 145 \\
\hline Grade 2 & 31 & 30 & 30 & 30 & 30 & 29 & & & 180 \\
\hline Grade 3 & 23 & 24 & 24 & 23 & 24 & 24 & & & 142 \\
\hline Grade 4 & 30 & 33 & 28 & 28 & 28 & 21 & & & 168 \\
\hline Grade 5 & 25 & 24 & 25 & 22 & 23 & 26 & & & 145 \\
\hline Grade 6 & 26 & 28 & 28 & 27 & & & & & 109 \\
\hline Grade 7 & 27 & 29 & 27 & 27 & 27 & & & & 137 \\
\hline Grade 8 & 30 & 28 & 29 & 29 & & & & & 116 \\
\hline Grade 9 & 28 & 30 & 27 & 27 & 25 & & & & 137 \\
\hline Grade 10 & 24 & 22 & 18 & & & & & & 64 \\
\hline Grade 11 & 19 & 23 & 19 & & & & & & 61 \\
\hline Grade 12 & 22 & 35 & & & & & & & 57 \\
\hline Grand Total &
\end{tabular}

\section{REVIEW OF LITERATURE}

\section{Language Maintenance and Language Shift}

According to Longman Dictionary of Language Teaching and Applied Linguistics (2002), language maintenance is the degree to which an individual or group continues to use their language, particularly in a bilingual or multilingual area or among immigrant groups; whereas language shift is the process by which a new language is acquired by a community usually resulting with the loss of the community's first language. Both language maintenance and language shift are the results of language contact situations. Since the publication of Fishman's (1966) Language Loyalty in the United States, there has been significantly a great amount of research on language maintenance and language shift (LMLS) as a linguistic contact phenomenon.

Language maintenance refers to the situation where speech community continues to use its traditional language in the face of a host of conditions that might foster a shift to another language. Veltman (1991) asserted that "language maintenance is the practice of speaking one's mother tongue throughout one's lifetime as the only language in daily use" (p. 147). Language ma intenance is also referred to as 'language survival' or 'language retention'. It is the product of language contact where a linguistic minority or a dominated ethnolinguistic group is successful in keeping its original language in spite of the pressure exhorted on it by a dominant linguistic group. Language shift, on the other hand, means that a community gives up entirely its language in favour of another one (Fishman, 1966). According to Weinreich (1964), language shift is the "change from the habitual use of one language to that of another one"(p. 68). Jaspert and Kroon (1993) defined language shift as "the gradual disappearance of a language in a community where it used to be spoken" (p. 293).

\footnotetext{
${ }^{4}$ Library of Congress - Federal Research Division, Country Profile: Eritrea, September 2005, p. 6 at http://memory.loc.gov/frd/cs/profiles/Eritrea.pdf, Accessed on Feb. $5^{\text {th }} 2011$

${ }^{5}$ The Eritrean Community Chairman Message on the Eritrean International School Website http://eritreaschool.com
} 
Recently, more research on LMLS has been conducted in different contexts. Okamura (1981), for instance, studied mother tongue maintenance and development among the Japanese children living in the United States. The results revealed that the years of schooling in the U.S. significantly related to the skill level in English. The parents proved to affect the child's language status, particularly the degree of his mother tongue maintenance. In terms of relative importance, the child's factors such as his/her interest, attitudes, and the extent of use of the language contributed more significantly to the level in each language. Morgan (1987) found that there was a shift to Spanish among Haitian community as a trend for the future rather than maintenance of Haitian Creole or establishment of both languages in a state of balanced bilingualism. Moreover, Brook (1988) investigated language maintenance and language shift among the Japanese community in the Los Angeles area.

Yakoubou (1994) said that English remains the overall language of communication in the households of the participating families. Since the children do not use the parents' African languages among themselves, there is evidence to suggest that those languages might not survive in the next generation. Furthermore, Saxena (1995) conducted a study on language maintenance and shift of Panjabi Hindus in Southall. He argues that the Panjabi, Hindi and English languages constituted the main verbal repertoire of the community. The findings also suggest that, even after 30 to 40 years of the minority community's establishment in Britain, English has not encroached enough on the family domain to threaten the survival of the minority languages. Furthermore, Kostoulas-Kostoulas-Makrakis (1995) carried out a research on the language maintenance and shift of Greek background students in Sweden. More Greek than Swedish is also maintained in communication between students and most of their Greek friends. There is a slow shift taking place among the second generation Greek students. Similarly, Stoessel (1998) investigated the social networks as a factor in language maintenance and shift. There was a strong association between maintenance ratings and the ratio of L1 to L2 speakers in the speaker's secondary network in the US The amount of L2-speaking kin in the US also correlated with language shift. In his study, Somerholter (1999) investigated language contact and shift in the Soviet German speech community. He argued that in Germany, exposure to new dialects of German, as well as the loss of the traditional family unit due to the circumstances of migration will hasten the end of Soviet German dialects and destroy what is left of that speech community.

Sun (2000) found that the importance of parental roles in first language maintenance in immigrant families. Parents' guidance and parents' insistence on their children's use of Chinese at home played an important role in their children's maintenance of Chinese language. In another study, Cashman (2001) examined the bilingual language practices in a small, heterogeneous, urban Latino community in the Midwestern United States. The individual variables such as age at time of arrival had the most significant impact on the Spanish language maintenance of Group 1(Latin American informants), while social network variables had the most significant impact on the Spanish language maintenance of Group 2(U.S.). Holdeman (2002) investigated language maintenance and shift among the Russian old believers of Erie in Pennsylvania. The research investigated the community's origins and history, its variant of Russian, and the status of Russian, Church Slavonic, and English, focusing on history, domains of use, attitudes toward the languages, proficiency, etc., and examined the process of language maintenance and shift in the community. Other studies on LMLS have been conducted in different circumstances like Venditti (2003) in his research, studied women and ethnic language maintenance of Italian immigrant family triads in Sainte-Leonard, Montreal. Biltoo(2004) studied Bhojpurias language maintenance and language shift in Mauritius, and Zhang (2005) studied he home language maintenance and acculturation among second-generation Chinese children.

Park (2007) in his research, maintaining Korean as a heritage language, found that the language use pattern within the family showed the language shift among Korean heritage language adolescents. However, it is not the place, but the parents that make home a heritage language domain. The pattern shows that Korean is used more with the parents' generation and English is predominantly used among peers in the younger generations. Hamid (2007) studied language maintenance and shift in the Sylheti community in Leeds. She claimed that the identification of Bangla as mother tongue is linked to reasons other than use. Analysis of data plainly indicated that Sylheti is strongest among immediate and extended family and friends. The maintenance of Sylheti is established and the evidence of Sylheti-English bilingualism substantiates the additive role of minority language in a bilingual context. In a relatively similar study concerned with Bangladeshis in diaspora, Subhan (2007) carried out a research on heritage language maintenance among Bangladeshi immigrants in Toronto. The findings suggested that language maintenance is not noticeable within the families of Bangladeshi immigrants in Toronto in profound or significant ways. Although the parents almost continually use heritage language and that other sources of heritage language sources are present in the home environment, children generally live in their own separate worlds and interact with heritage language sources and users only on a functional level. Most of the outside contexts and resources of heritage language is avoided by the children and sometimes neglected by the parents. Parents are generally found to consciously foster and transmit some religious values and cultural behaviour.

Marongiu (2007) Investigated language maintenance and shift in Sardinia by Sardinian and Italian in Cagliari. Ramirez (2007) studied language attrition and language maintenance of Colombian immigrants in New York State. The results of this study indicate that first generation Colombian immigrants in New York State do not present signs of language attrition but some pragmatic changes due to exposure to English as well as to other Spanish dialects. These 
bilinguals register a high level of first language maintenance due to the fact that they keep using their native language for both integrative and instrumental processes.

Garcia (2008) examined the role of language ideology and life choices in language maintenance and language shift across three generations of a Cuban American family in the United States in a cross generational study. He found that the unique circumstances of Cuban Americans help to inform their decisions on language maintenance across generations and that language ideology and other life choices play a pivotal role in the maintenance of the Spanish language or the language shift to English with this family. Van Aswegen (2008) studied language maintenance and shift of Maale, a minority language spoken in Ethiopia. The findings indicated that the mother tongue literacy programme contributed to language maintenance but it was a stepping stone to further education, which favours the learning of a second language, which could lead to possible attrition of the mother tongue. Brown (2008) investigated language shift and maintenance through the examination of language usage across four generations as self-reported by university students in Belarus in terms of self-reported concern about the future of Belarusian and the extent to which language use with prospective children reflects that concern.

Martin (2009) carried out a research on Arab American parents' attitudes toward their children's heritage language maintenance and language practices. Results indicated that parents hold positive attitudes towards Arabic and engage in various language practices that promote the maintenance of Arabic in their families, and racism is not significantly associated with language attitudes or language encouragement. Gogonas (2009) studied language shift in second generation Albanian immigrants in Greece. The data on children's language competence and on patterns of language use within Albanian households indicated that the Albanian ethnolinguistic group was undergoing rapid language shift. Soufo (2009) studied language shift and maintenance within three generations for three Turkish-Arabic speaking families. Language patterns in three Arabic-Turkish bilingual families were investigated through deep interviews held with third-generation representatives of each families. The results showed that shift or maintenance take different directions within three generations because of, mostly, outside factors shaping the attitude of bilingual speakers. Letsholo (2009) carried out a research on language maintenance or shift through investigating the attitudes of Bakalanga youth towards their mother tongue. The results showed that informants used Setswana frequently, even in domains where they could use their mother tongue, e.g. when speaking to peers from the same mother tongue. Some of the subjects also expressed negative feelings towards using their mother tongue around non-native speakers of the language.

Matsumoto (2010) examined the role of social networks in the post-colonial multilingual island of Palau in terms of the mechanisms of language maintenance and shift. He explored the usefulness of social networks from three perspectives, investigating whether and how social networks can explain changes in the use of former colonial languages in a post-colonial community; the functions of strong and weak ties in a multilingual community; and the social characteristics of communities in which social network as an analytical tool may have an explanatory force. He concluded that the social network is indeed a valuable and important social variable in sociolinguistic investigations, alongside other factors, such as sex and identity. Finally, and in somehow two similar situations, Zhang (2010) investigated language maintenance and language shift among Chinese immigrant parents and their second-generation children in the United States, and Xie (2010) examined first language maintenance and attrition among young Chinese adult immigrants in the US, too.

\section{RESEARCh DESIGN}

\section{A. Objectives and Research Questions}

The aim of this study is to examine language maintenance and language shift among second generation Tigrinya speaking Eritrean teenagers and explore the factors affecting these phenomena such as age, gender, religion, number of siblings, birth order, number of siblings born in Saudi Arabia, enrolment in Tigrinya class and language background. It sought answers to the following questions:

1. How proficient are the Eritrean teenager immigrants in both Tigrinya and Arabic?

2. Are the Eritrean teenager immigrants maintaining their Tigrinya language or shifting to Arabic?

3. Are the Tigrinya speakers proud of their linguistic and cultural identity?

\section{B. Research Method}

\section{The Sample}

For the purpose of the current research, sixty-four Tigrinya speaking teenager immigrants in Riyadh were randomly chosen. Forty of them are females; whereas twenty-four are males. These respondents are students enrolled in the Eritrean International School in Riyadh. They are sampled from the eleventh and twelfth grades.

\section{The Research Tool}

A questionnaire of sixty-two items was developed to elicit information from the Tigrinya speaking Eritrean teenagers. The questionnaire items focused on the respondents' self-perception of the following dimensions: proficiency in Tigrinya ( 5 items, $\alpha=0.88$ ); proficiency in Arabic ( 5 items, $\alpha=0.81$ ); the use of Tigrinya at home ( 7 items $\alpha=0.91$ ); and the use of Arabic at home ( 7 items $\alpha=0.94$ ); the use of Tigrinya in public (7 items $\alpha=0.90)$ and the use of Arabic in 
Public ( 7 items $\alpha=0.92$ ); and finally the identity of Tigrinya ( 7 items $\alpha=0.72$ ), and the identity of Arabic ( 5 items $\alpha=$ $0.70)$.

\section{Procedure}

The data were collected through a questionnaire distributed to the young informants and filled by them. The collection of the forms took about ten days since the date of distribution. The teachers, who were in charge of teaching the upper classes in the school, i.e. classes $11^{\text {th }}$ and $12^{\text {th }}$, were asked to convey the instructions of answering the questionnaire items. Those teachers distributed the forms to their students, collected them back, and submitted them to the administration as agreed with the Principal of the school, who eventually submitted the questionnaire forms to the researcher.

\section{FINDINGS AND DiSCUSSION}

\section{A. Demographic Profile}

A total of sixty-four second generation Tigrinya speaking teenagers, twenty-four males and forty females, participated in the survey. Their ages range between 16 to 22, as shown in table 2 below.

TABLE 2 .

AGE GROUP OF THE RESPONDENTS

\begin{tabular}{|l|l|l|l|}
\hline No. & Age Group & Frequency & Percentage \\
\hline $\mathbf{1}$ & 22 & 2 & 3 \\
\hline $\mathbf{2}$ & 21 & 1 & 1.6 \\
\hline $\mathbf{3}$ & 20 & 5 & 7.8 \\
\hline $\mathbf{4}$ & 19 & 19 & 29.7 \\
\hline $\mathbf{5}$ & 18 & 20 & 31 \\
\hline $\mathbf{6}$ & 17 & 14 & 21.9 \\
\hline $\mathbf{7}$ & 16 & 3 & 4.7 \\
\hline
\end{tabular}

The majority (65.63\%) of them are Muslims, whereas $34.37 \%$ are Christians. $95 \%$ of the participants were born in Saudi Arabia and only $5 \%$ were born in Eritrea. They ranged from being the first-born child to being the sixth. Regarding the birth order, the largest group (35.94\%) was the first oldest in their family birth order. As for siblings born in Saudi Arabia, the largest group (28\%) got three sisters and brothers who were born in Saudi Arabia, whereas the second largest group (22\%) got four sisters and brothers who were born in Saudi Arabia. Nevertheless, $78 \%$ of them have been enrolled in a Tigrinya language medium school and $22 \%$ have never been enrolled in Tigrinya language medium school. $61 \%$ of the respondents claimed that their mother tongue is Tigrinya, whereas only $39 \%$ of them claim that Arabic is their mother tongue. $98 \%$ of the respondents' fathers and $94 \%$ of their mothers consider Tigrinya as their mother tongue.

\section{B. Tigrinya and Arabic Proficiency}

The results showed that the respondents have relatively a limited proficiency in their mother tongue. To have a clear idea we refer to the respondents rating scale from 1 to 4 (strongly disagree to strongly agree), as shown in table 3 below. The statistics show that the respondents have limited ability to read and write in Tigrinya. Reading and writing have the least ability. $48 \%$ of the respondents read Tigrinya fluently, $x^{2}=3.37$ and about $47 \%$ of them write Tigrinya fluently, $x^{2}$ $=1.37$ and show no significance. They also have a limited ability in understanding and speaking Tigrinya. More than $78 \%$ of the respondents claim that they understand Tigrinya fluently, $\mathrm{x}^{2}=25.25(\mathrm{p} \square 0.01)$, whereas more than $76 \%$ speak Tigrinya fluently, $\mathrm{x}^{2}=20.87(\mathrm{p} \square 0.01)$. Respondents' oral skills in translation are better than their ability in both reading and writing, $\mathrm{x}^{2}=22.50,(\mathrm{p}<0.01)$.

The respondents show a relatively greater proficiency in Arabic than in Tigrinya and this can be seen through the results below. More than $98 \%$ of the respondents claim that they understand Arabic fluently, $x^{2}=46.15,(p<0.01)$. However, $96.9 \%$ of the respondents agree with the statement related to speaking Arabic, $\mathrm{x}^{2}=30.87,(\mathrm{p}<0.01)$. More than $85.9 \%$ of the respondents agree with the statement related to reading Arabic fluently, $\mathrm{x}^{2}=23.9(\mathrm{P}<0.01)$ and $87.5 \%$ of them agree with the statement related to wring Arabic, $\mathrm{x}^{2}=40.25(\mathrm{p}<0.01)$. As for the ability to translate Arabic into Tigrinya orally, $76.5 \%$ of the respondents agree with the statement, $x^{2}=24.37,(p<0.01)$. Therefore, many second-generation teenagers have experienced language shift and have become proficient in Arabic, their second language. 
TABLE 3.

THE CHI SQUARE STATISTICS OF TIGRINYA AND ARABIC PROFICIENCY

\begin{tabular}{|l|l|l|l|l|l|l|}
\hline No. & Statement S D & D & A & SA & $\mathbf{x 2}$ \\
\hline $\mathbf{1}$ & I understand Tigrinya fluently & 1 & 13 & 27 & 23 & $25.25^{* *}$ \\
\hline $\mathbf{2}$ & I speak Tigrinya fluently & 3 & 12 & 26 & 23 & $20.87^{* *}$ \\
\hline $\mathbf{3}$ & I read Tigrinya fluently & 12 & 21 & 18 & 13 & 3.37 \\
\hline $\mathbf{4}$ & I write Tigrinya fluently & 17 & 17 & 18 & 12 & 1.37 \\
\hline $\mathbf{5}$ & I can translate orally Tigrinya into Arabic easily and accurately & 2 & 14 & 28 & 20 & $22.50^{* *}$ \\
\hline $\mathbf{6}$ & I understand Arabic fluently & 0 & 1 & 18 & 45 & $46.15^{* *}$ \\
\hline $\mathbf{7}$ & I speak Arabic fluently & 0 & 2 & 24 & 38 & $30.87^{* *}$ \\
\hline $\mathbf{8}$ & I read Arabic fluently & 0 & 9 & 16 & 39 & $23.09^{* *}$ \\
\hline $\mathbf{9}$ & I write Arabic fluently & 1 & 7 & 23 & 33 & $40.25^{* *}$ \\
\hline $\mathbf{1 0}$ & I can translate orally Arabic into Tigrinya easily and accurately & 2 & 13 & 29 & 20 & $24.37 * *$ \\
\hline
\end{tabular}

**Chi square is significant at $0.01 \quad \mathrm{SA}=$ Strongly Agree

\section{Language Maintenance and Language Shift}

\section{a. Language Used at Home}

Table 4 shows that chi square statistics are higher in parents' usage of Tigrinya when speaking to their teenagers. Therefore, parents usually prefer to speak Tigrinya with their children. More than $85 \%$ of the teenagers say that their mothers use Tigrinya when they talk to them at home, $x^{2}=68.03$, ( $\left.<<0.01\right)$. More than $89 \%$ of them also confirm that their fathers prefer Tigrinya to talk to them at home, $\mathrm{x}^{2}=41.87,(\mathrm{p}<0.01)$. On the other hand, the teenagers use Tigrinya to speak to their parents but with less interest than the parents do. They speak to their parents to express their feelings of solidarity with the elders' wish in maintaining the mother tongue. About $73 \%$ of the teenagers claim that they use Tigrinya to speak to their mothers at home, $\mathrm{x}^{2}=35.53$, ( $\left.<<0.01\right)$; whereas $75 \%$ of them say that they use Tigrinya when they talk to their fathers $x^{2}=36.93$, $(p<0.01)$. Anyway, when teenagers speak to their brothers and sisters in the home, they also use Tigrinya but, as statistics show, this is with less interest than the parents do. About $53 \%$ of the teenagers say that they use Tigrinya to talk to their brothers and sisters with chi square 7.09, and it is not statistically significant at all. Similarly, when the teenagers speak to their friends in the home they use Tigrinya in a limited way $(40 \%), x^{2}=9.12$ and it is not statistically significant. The respondents use Tigrinya in a limited way when they speak or think to themselves in the home, that is, about $31 \%$ of them agree with the statement "I generally use Tigrinya when I think or talk to myself when I am at home", $x^{2}=3.50$, which does not statistically show any significance at all.

TABLE 4.

THE CHI SQUARE STATISTICS OF LANGUAGE USED AT HOME

\begin{tabular}{|c|c|c|c|c|c|c|c|}
\hline No. & Statement & NA & SD & D & $\mathbf{A}$ & SA & $\mathbf{x 2}$ \\
\hline 11 & My mother generally speaks Tigrinya to me at home & 4 & 1 & 4 & 19 & 36 & $68.03 * *$ \\
\hline 12 & My father generally speaks Tigrinya to me at home & 2 & 0 & 5 & 24 & 33 & $41.87 * *$ \\
\hline 13 & I generally speak Tigrinya to my mother at home & 3 & 2 & 12 & 21 & 26 & $35.53 * *$ \\
\hline 14 & I generally speak Tigrinya to my father at home & 4 & 1 & 11 & 25 & 23 & $36.93 * *$ \\
\hline 15 & I generally speak Tigrinya to my sisters and brothers at home & 6 & 12 & 12 & 19 & 15 & 7.09 \\
\hline 16 & I generally speak Tigrinya to my friends at home & 6 & 13 & 19 & 17 & 9 & 9.12 \\
\hline 17 & I generally use Tigrinya when I think or talk to myself when I am at home & 13 & 18 & 13 & 11 & 9 & 3.50 \\
\hline 18 & My mother generally speaks Arabic to me at home & 9 & 11 & 17 & 16 & 11 & 3.81 \\
\hline 19 & My father generally speaks Arabic to me at home & 9 & 13 & 20 & 15 & 7 & 8.18 \\
\hline 20 & I generally speak Arabic to my mother at home & 6 & 8 & 16 & 20 & 14 & $10.37 *$ \\
\hline 21 & I generally speak Arabic to my father at home & 6 & 10 & 18 & 19 & 11 & $9.59 *$ \\
\hline 22 & I generally speak Arabic to my sisters and brothers at home & 7 & 4 & 6 & 18 & 29 & $34.90 * *$ \\
\hline 23 & I generally speak Arabic to my friends at home & 5 & 4 & 4 & 18 & 33 & $50.84 * *$ \\
\hline 24 & I generally use Arabic when I think or talk to myself when I am at home & 6 & 7 & 5 & 16 & 30 & $34.90 * *$ \\
\hline
\end{tabular}

*Chi square is significant at $0.05 \quad \mathrm{NA}=$ Not Applicable $\mathrm{SD}=$ Strongly Disagree, $\mathrm{D}=$ Disagree, $\mathrm{A}=\mathrm{Agree}$, $* *$ Chi square is significant at $0.01 \quad \mathrm{SA}=$ Strongly Agree

In contrast, parents seem to use Arabic in a limited way when they speak to their children in the home. Mothers seem to be reluctant to use Arabic in speaking to their children at home (42\%) and the chi square is 3.81, which is not statistically significant. The fathers, on the other hand, use Arabic in a limited way for the same purpose (34\%), with chi square 8.18 and this is also not statistically significant. When talking to their parents, the teenagers seem not to be favouring using Arabic. About 53\% of them use Arabic to talk to their mothers at home, $x^{2}=10.37,(p<0.05)$, and about $47 \%$ of them also use Arabic when they talk to their fathers at home, $x^{2}=9.59,(p<0.05)$. We also find that the teenagers use Arabic more than Tigrinya when they talk to their sisters and brothers at home $(73.48 \%), \mathrm{x}^{2}=34.90,(\mathrm{p}<$ $0.01)$. About $80 \%$ of the teenagers use Arabic when they talk to their friends in the home, $x^{2}=50.84,(p<0.01)$ and about $72 \%$ of them use Arabic when they think or talk to themselves, $x^{2}=34.90,(p<0.01)$.

b. Language Used in Public Places

As for the language used in public places by the teenagers and their parents when talking to each other, it is found that mothers and fathers use Tigrinya more than Arabic in public places when they are talking to their children. The respondents claim that $71.87 \%$ of the mothers prefer to use Tigrinya in public places when they talk to their children, $x^{2}$ 
$=31,(p<0.01)$. Also $71.87 \%$ of the fathers use Tigrinya when talking to their children, $x^{2}=28.81,(p<0.01)$. The teenagers, on the other hand, seem to use Tigrinya more than Arabic when they speak with their parents in public places. Less than $58 \%$ of them clam that they prefer Tigrinya to Arabic when they talk to their mothers in public places, $\mathrm{x}^{2}$ $=15.53,(\mathrm{p}<0.01)$, whereas less than $61 \%$ prefer to use Tigrinya when talking to their fathers in public, $x^{2}=14.75$, $(\mathrm{p}<0.10)$. The teenagers do not seem to be willing to use Tigrinya when they talk to their brothers and sisters in public places. Only $40.62 \%$ of them use Tigrinya when talking to their siblings with chi square 2.09, which is not statistically significant at all. In contrast, we find them prefer Tigrinya to Arabic when they talk to their friends in public places $(76.56 \%), x^{2}=21.62,(p<0.01)$. Only about $39 \%$ of the teenagers use Tigrinya more than Arabic When they think or talk to themselves in public, $\mathrm{x}^{2}=6.62$, which is not significant as well. The mothers do not prefer using Arabic in talking to their children in public, as it is clear in the respondent's answers to statement 32, in table 5 below; $51.56 \%$ of the respondents claim that their mothers Arabic in talking to their children in public places, $x^{2}=8.69$. We also find that the fathers, on the other hand, use Arabic more than Tigrinya in such situations (50\%) and $\mathrm{x}^{2}=10.53$.

TABLE 5.

THE CHI SQUARE STATISTICS OF LANGUAGE USED AT HOME

\begin{tabular}{|c|c|c|c|c|c|c|c|}
\hline No. & Statement & NA & SD & D & $\mathbf{A}$ & $\mathbf{S A}$ & $\mathbf{x 2}$ \\
\hline 25 & My mother generally speaks Tigrinya to me in public & 3 & 9 & 6 & 19 & 27 & $31.00 * *$ \\
\hline 26 & My father generally speaks Tigrinya to me in public & 3 & 7 & 8 & 25 & 21 & $28.81 * *$ \\
\hline 27 & I generally speak Tigrinya to my mother in public & 4 & 9 & 14 & 14 & 23 & $15.53 * *$ \\
\hline 28 & I generally speak Tigrinya to my father in public & 5 & 7 & 13 & 18 & 21 & $14.75^{* *}$ \\
\hline 29 & I generally speak Tigrinya to my sisters and brothers in public & 9 & 16 & 13 & 14 & 12 & 2.09 \\
\hline 30 & I generally speak Tigrinya to my friends in public & 7 & 5 & 11 & 26 & 15 & $21.62 * *$ \\
\hline 31 & I generally use Tigrinya when I think or talk to myself when I am in public & 7 & 19 & 13 & 15 & 10 & 6.62 \\
\hline 32 & My mother generally speaks Arabic to me in public & 8 & 6 & 17 & 16 & 17 & 8.69 \\
\hline 33 & My father generally speaks Arabic to me in public & 6 & 8 & 18 & 19 & 13 & $10.53^{*}$ \\
\hline 34 & I generally speak Arabic to my mother in public & 6 & 4 & 16 & 15 & 23 & $18.96^{* *}$ \\
\hline 35 & I generally speak Arabic to my father in public & 5 & 6 & 13 & 20 & 20 & $16.46^{* *}$ \\
\hline 36 & I generally speak Arabic to my sisters and brothers in public & 6 & 3 & 6 & 15 & 34 & $50.21 * *$ \\
\hline 37 & I generally speak Arabic to my Tigrinya speaking friends in public & 3 & 7 & 5 & 29 & 20 & $39.43 * *$ \\
\hline 38 & I generally use Arabic when I think or talk to myself when I am in public & 8 & 6 & 7 & 18 & 25 & $21.78 * *$ \\
\hline
\end{tabular}

In contrast, the teenagers use Arabic more than Tigrinya to talk to their parents in public. 59. $37 \%$ of the teenagers say that they prefer to use Arabic to talk to their mothers; $x^{2}=18.96$, $(p<0.01)$, and more than $62 \%$ of them prefer Arabic as well to talk to their fathers in public, $x^{2}=16.46,(p<0.01)$. The teenagers prefer using Arabic more than Tigrinya when they talk to their siblings in public $(76.56 \%)$, and $x^{2}=50.21$, $(\mathrm{p}<0.01)$. We also found that $64.06 \%$, of the teenagers prefer Arabic to Tigrinya again when they talk to their friends, $x^{2}=21.62(p<0.01)$. Meanwhile, 67.18\% of them use Arabic when they think and talk to themselves in public, $\mathrm{x}^{2}=21.78(\mathrm{p}<0.01)$.

c. Tigrinya and Arabic Language Identity

Table 6 below shows the respondents opinions about the importance of maintaining Tigrinya. A very high number of the respondents find that Tigrinya is useful when dealing with elders, dealing with monolinguals, maintaining culture, and attending cultural activities such as rituals and marriages. More than $98 \%$ of the respondents think that speaking Tigrinya is generally useful for talking with Tigrinya speaking elders, $x^{2}=48.78,(p<0.01)$. The teenagers are aware of their mother tongue maintenance and their culture as well, so we find that more than $95.31 \%$ of them believe that speaking Tigrinya is essential in maintaining Tigrinya speakers culture, $x^{2}=59.62,(p<0.01)$. Only $28 \%$ of the respondents think that Tigrinya is useful for work purposes, $x^{2}=18.87,(p<0.01)$. About $33 \%$ of the respondents think that Tigrinya is useful for travelling purposes, whereas $56 \%$ of them think that Tigrinya is useful to help Tigrinya monolinguals. About $94 \%$ think that maintaining Tigrinya is important, $\mathrm{x}^{2}=85.12,(\mathrm{p}<0.01)$, and $81 \%$ of the teenagers think that attending cultural activities in Tigrinya language, such as rituals and marriage celebrations, helps in maintaining Tigrinya, $x^{2}=26.25,(p<0.01)$. They are fully aware that Arabic is not helpful in maintaining their mother tongue, rather they think it is helpful in certain important purposes of life such as work purposes, and travelling around. Although teenagers prefer Arabic to Tigrinya in different situations both in their houses and in public, they feel that Tigrinya is to be maintained through culture maintenance. They also seem to use Tigrinya more than Arabic when dealing with elders, which reflects the older generation's desire to maintain culture through language maintenance 
TABLE 6.

THE CHI SQUARE STATISTICS OF TIGRINYA AND ARABIC LANGUAGE IDENTITY

\begin{tabular}{|c|c|c|c|c|c|c|}
\hline No. & Statement & SD & $\mathbf{D}$ & $\mathbf{A}$ & SA & $\mathbf{x 2}$ \\
\hline 39 & Speaking Tigrinya is generally useful for talking with Tigrinya speaking elders & 0 & 1 & 17 & 46 & $48.78 * *$ \\
\hline 40 & Speaking Tigrinya is generally useful for maintaining Tigrinya speakers culture & 1 & 2 & 23 & 38 & $59.62 * *$ \\
\hline 41 & Speaking Tigrinya is generally useful for work & 21 & 25 & 16 & 2 & $18.87 * *$ \\
\hline 42 & Speaking Tigrinya is generally useful when travelling & 12 & 31 & 14 & 7 & $20.37 * *$ \\
\hline 43 & Speaking Tigrinya is generally useful for helping Tigrinya monolinguals & 3 & 5 & 23 & 33 & $39.25 * *$ \\
\hline 44 & Maintaining Tigrinya is important & 2 & 2 & 13 & 47 & $85.12 * *$ \\
\hline 45 & $\begin{array}{l}\text { Attending cultural activities in Tigrinya language such as rituals, and marriages are } \\
\text { helpful in maintaining Tigrinya language }\end{array}$ & 5 & 7 & 23 & 29 & $26.25 * *$ \\
\hline 46 & Speaking Arabic is generally useful for talking with Tigrinya speaking elders & 16 & 24 & 11 & 13 & 6.12 \\
\hline 47 & Speaking Arabic is generally useful for maintaining Tigrinya speakers culture & 13 & 28 & 16 & 7 & $14.62 * *$ \\
\hline 48 & Speaking Arabic is generally useful for work & 1 & 2 & 21 & 40 & $63.87 * *$ \\
\hline 49 & Speaking Arabic is generally useful when travelling & 0 & 4 & 28 & 32 & $21.50 * *$ \\
\hline 50 & Speaking Arabic is generally useful for helping Tigrinya monolinguals & 9 & 22 & 18 & 15 & 5.62 \\
\hline
\end{tabular}

\section{Relationships that Affect Language Maintenance and Language Shift}

To see if variables of the data are positively associated, correlation coefficients and significance levels were computed. The resulting correlations indicate that variables of the data are within a range of .358 to .852 . Correlation coefficients with an asterisk mean that the variable relationship is significant at $\mathrm{p}<.05$ and two asterisks, at $\mathrm{p}<.01$. Because of the closely interrelated associations of the nature of the variables, there is an abundance of correlation coefficient at $\mathrm{p}<.05$ and at $\mathrm{p}<01$. To condense the correlation coefficients, group variables have been calculated. Table 7 reveals the group variable relationships among proficiency in Tigrinya and Arabic, Tigrinya and Arabic used at home and in public, and Tigrinya and Arabic language identity. The correlation showed that Tigrinya teenagers who have a proficiency in Tigrinya use Tigrinya at home and in public. Those teenagers who also have a proficiency in Tigrinya have a strong sense of Tigrinya identity. Those who have a proficiency in Arabic use more Arabic at home and in public, but not necessarily a strong sense of Arabic identity.

TABLE 7.

CORRELATION COEFFICIENT OF THE OVERALL VARIABLES AFFECTING LMLS IN THIS STUDY

\begin{tabular}{|l|l|l|l|l|l|l|l|l|}
\hline & TGL & ARL & TGH & ARH & TGP & ARP & TGI & ARI \\
\hline TGL & 1 & .001 & $.586^{* *}$ & $-.422^{* *}$ & $.524^{* *}$ & -.124 & $.411^{* *}$ & .197 \\
\hline ARL & .001 & 1 & $-.363^{* *}$ & $.426^{* *}$ & $-.292^{*}$ & $.358^{* *}$ & .079 & -.011 \\
\hline TGH & $.586^{* *}$ & $-.363^{* *}$ & 1 & $-.642^{* *}$ & $.851^{* *}$ & $-.420^{* *}$ & $.385^{* *}$ & .135 \\
\hline ARH & $-.422^{* *}$ & $.426^{* *}$ & $-.642^{* *}$ & 1 & $-.626^{* *}$ & $.641^{* *}$ & -.146 & .066 \\
\hline TGP & $.524 * *$ & $-.292^{*}$ & $.851^{* *}$ & $-.626^{* *}$ & 1 & $-.507 * *$ & $.482^{* *}$ & .118 \\
\hline ARP & -.124 & $.358^{* *}$ & $-.420^{* *}$ & $.641^{* *}$ & $-.507 * *$ & 1 & -.069 & .192 \\
\hline TGI & $.411^{* *}$ & .079 & $.385^{*}$ & -.146 & $.482^{* *}$ & -.069 & 1 & .160 \\
\hline ARI & .197 & -.011 & .135 & .066 & .118 & .192 & .160 & 1 \\
\hline
\end{tabular}

TGL=Tigrinya Language Proficiency $\quad$ ARL=Arabic Language Proficiency $\quad$ TGH=Tigrinya Language Used at Home $\mathrm{ARH}=$ Arabic Language Used at Home TGP=Tigrinya Language Used in Public $\quad \mathrm{ARP}=\mathrm{Arabic}$ Language Used in Public TGI= Tigrinya Language Identity ARI= Arabic Language Identity

The demographic variables such as age, gender, religion, number of siblings, birth order, number of siblings born in Saudi Arabia, enrolment in Tigrinya class, and language background were discussed in terms of correlation with group variables related to LMLS. These group variables include proficiency in Tigrinya and Arabic group variables, Tigrinya and Arabic used at home group variables, Tigrinya and Arabic used in public group variables, and Tigrinya and Arabic language identity group variables. It is found that only some of these demographic variables have some correlations with some of the above mentioned group variables. variable, for instance, correlates positively with some of these variables and negatively with others. Religion correlates positively with Tigrinya language proficiency, $r=.360,(p<.01)$, while it correlates negatively with Arabic language proficiency, $r=-.298,(\mathrm{p}<.05)$. Again, we find that religion correlates positively with Tigrinya language use at home, $r=.469,(\mathrm{p}<.01)$; whereas it correlates negatively with Arabic, $r=-.574$, $(\mathrm{p}<.01)$. Religion variable also correlates with the group variables related to the type of language used in public. It correlates positively with Tigrinya language use in public, $r=.501,(\mathrm{p}<.01)$, but it correlates negatively with Arabic language use in public, $\mathrm{r}=-.359,(\mathrm{p}<.01)$. As we have seen earlier, 66\% of the respondents claimed that they are Muslims and only $34 \%$ of them claimed that they are Christians.

Moreover, the respondents' first language variable correlates positively and negatively with these group variables. We find that the respondent's first language variable correlates with Tigrinya language proficiency, $\mathrm{r}=-.358,(\mathrm{p}<.01)$, while it correlates positively with Arabic language proficiency, $\mathrm{r}=.345,(\mathrm{p}<.01)$. It also correlates negatively with Tigrinya use at home, $\mathrm{r}=-.635(\mathrm{p}<.01)$, but it correlates positively with Arabic use at home, $\mathrm{r}=.591(\mathrm{p}<.01)$. Again we find that the respondents' first language variable correlates negatively with Tigrinya use in public, $\mathrm{r}=-.572(\mathrm{p}<.01)$, but it correlates positively with Arabic use in public, $\mathrm{r}=-384(\mathrm{p}<.01)$. 
As for the other demographic variables like age, gender number of siblings, birth order, number of siblings born in Saudi Arabia, and enrolment in Tigrinya class, there was no correlation, with the other variables related to LMLS, has been observed.

\section{CONCLUSION}

The results from this research reveal that second generation Tigrinya teenagers have a limited ability to understand, speak, read, write, and translate orally Tigrinya into Arabic and vice-versa. In comparing the level of their proficiency in both Tigrinya and Arabic it is found that they have a lower proficiency in Tigrinya than in Arabic. Second generation Tigrinya teenagers speak Tigrinya mostly at home because their parents generally speak to them in Tigrinya, but the teenagers are able to understand, speak, read, and write in Arabic better than Tigrinya. Most of the participants choose Arabic over Tigrinya when communicating with brothers and sisters. This preference for Arabic over Tigrinya is due to a limited vocabulary in Tigrinya as compared to Arabic. Furthermore, the Arabic language is evidently the dominant language among the teenagers since they generally think or talk to themselves in Arabic independent of whether they are at home or in public.

This study reveals a correlation between Tigrinya and Arabic language proficiency, Tigrinya language usage at home and in public, and identity through Tigrinya and Arabic. The results indicate that bilingual Tigrinya teenagers who speak Tigrinya frequently at home and in public have a sense of Tigrinya identity through mother tongue. Those who are proficient in both Tigrinya and Arabic have a strong sense of Tigrinya language identity. Proficiency in Tigrinya is related to how much Tigrinya is spoken by the teenagers at home and in public. Those who are the most proficient in Tigrinya generally speak more Tigrinya at home and in public; and those who speak mostly Arabic at home speak only Arabic in public.

The use of Tigrinya is seemingly decreasing and the use of Arabic is increasing. Therefore, there is evidence from this study that second-generation Tigrinya teenagers' proficiency is shifting toward Arabic rather than maintaining the native language. This general trend of native language loss as a new language learned is also found in other parallel studies. Fillmore (1991:323) reported that “... once these children learn English, they tend not to maintain or to develop the language spoken at home, even if it is the only one their parents know." These Tigrinya teenagers in Saudi Arabia are gradually losing their mother tongue because they have acquired Arabic to survive in an Arabic-dominated society. In their daily communication with most of the people, they must use Arabic. Nevertheless, they have a deep appreciation of their native language, and acknowledge the fact that Tigrinya language with culture and ethnic background, contribute to their identity.

Efforts to maintain the Tigrinya language in the future will depend on the desire of individuals to hold on to their native language, culture, and identity. Essentially language maintenance will be reflected in the existence and desirability of the mother tongue, and the "forms of multilingual and multicultural accommodations" that are made (Edward, 1997). This study shows that Tigrinya second generation teenagers acquire Arabic rapidly and give little effort to retain their native language. It is important for them to maintain Tigrinya so that they can be bilingual and capable of working for both Tigrinya and non-Tigrinya people. Meanwhile, they can be proud of who they are and be able to understand their parents and Tigrinya monolinguals.

\section{REFERENCES}

[1] Appleyard, D. (2006). Tigrinya Language, in Brown, K., Ogilvie (2009). Concise encyclopaedia of languages of the world. Oxford: Elsevier Ltd.

[2] Biltoo, A. K. (2004). Language maintenance and language shift in Mauritius: A sociolinguistic investigation into the language practices of Bhojpurias. Unpublished D.Phil. dissertation. The University of York, United Kingdom, AAT C824904, http://proquest.umi.com, accessed on April 12, 2011.

[3] Brook. K.L. (1988). Language maintenance in the Japanese American community in the Los Angeles area. Unpublished M.A thesis. California State University, Long Beach, AAT 1335085, http://proquest.umi.com, accessed on March7, 2011.

[4] Brown, K., Ogilvie, S. (2009). Concise encyclopaedia of languages of the world. Oxford: Elsevier Ltd.

[5] Brown, N.A.(2008). Language shift or maintenance? An examination of language Usage across four generations as selfreported by university age students in Belarus. Journal of multilingual and multicultural development, 29 (1), pp. 1- 15.

[6] Cashman, H. R. (2001). Doing being bilingual: Language maintenance, language shift, and conversational code-switching in southwest Detroit, Ph.D. dissertation. University of Michigan, AAT 3016817, http://proquest.umi.com, accessed on May 16, 2011.

[7] Edwards, J. (1997). Language minority and language maintenance. In W. Grabe (Ed.), Annual Review of Applied Linguistics (pp.30-42). Flagstaff, AZ: Cambridge University Press.

[8] Fillmore, L.W. (1991). When learning a second language means losing the first. Early Childhood Research Quarterly. 6(3), 323-346

[9] Fishman, J.A. (1966). Language Loyalty in the United States. The Hague: Mouton.

[10] Garcia, D.L. (2008). En esta casa se hablaespanol. The role of language ideology and life choices in language maintenance and language shift across three generations of a Cuban American family in the United States, unpublished Ph.D. dissertation, Stanford University, AAT 333282, http://proquest.umi.com, accessed on July 2, 2010.

[11] Gogonas, N. (2009). Language shift in second generation Albanian immigrants in Greece. Journal of Multilingual and Multicultural Development, Vol. 30, No. 2, pp. $95-110$. 
[12] Hamid, S. (2007). A study of language maintenance and shift in the Sylheti community in Leeds, Ph.D. dissertation, the University of York (United Kingdom), AAT C828283

[13] Holdman, J.D. (2002).Language maintenance and shift among the Russian Old Believers of Erie, Pennsylvania, Ph.D., The Ohio State University,; AAT 3059263, http://proquest.umi.com, accessed on May 15, 2011.

[14] Jaspert, K., \&Kroom, S. (1991). Social determinations language shift by Italians in the Netherlands and Flanders. International Journal of the Sociology of Language, 90, pp. 77-96.

[15] Kostoulas-Makrakis, N. (1995). Language maintenance or shift? A study of Greek background students in Sweden, Ph.D. dissertation, Stockholm Universitet (Sweden), AAT C435258, http://proquest.umi.com, accessed on April 12, 2011.

[16] Letsholo, R.(2009). Language maintenance or shift? Attitudes of Bakalanga youth towards their mother tongue, International Journal of Bilingual Education and Bilingualism, 12 (5), pp. 581_595.

[17] Lewis, M.P. (2009). Ethnologue: Languages of the world. $16^{\text {th }}$ ed. Dalas, Tex.: SIL International. Online version: http://www.ethnologue.com , accessed on January 5, 2011.

[18] Marongiu, M.A. (2007). Language maintenance and shift in Sardinia: A case study of Sardinian and Italian in Cagliari, Ph.D. dissertation, University of Illinois at Urbana-Champaign, AAT 3290312, http://proquest.umi.com, accessed on April 5, 2011.

[19] Martin, N. (2009). Arab American parents' attitudes toward their children's heritage language maintenance and language practices, unpublished M.A. thesis, The University of North Carolina at Chapel Hill, AAT 1472860, http://proquest.umi.com , accessed on May 20,2010.

[20] Matsumoto , K. (2010) The role of social networks in the post-colonial multilingual island of Palau: Mechanisms of language maintenance and shift, Multilingua, 29, pp. 133-165.

[21] Morgan, N.T. (1987).Language maintenance and shift among Haitians in the Dominican Republic, Ph.D. dissertation, The University of New Mexico, 1987, 164 pages; AAT 8808137, http://proquest.umi.com, accessed on June 17, 2011.

[22] Okamura, F. (1981). Mother tongue maintenance and development among the Japanese children living in the united states, Unpublished Ph.D. Thesis, University of California, Los Angeles, AAT 8206061, http://proquest.umi.com, accessed on April 15, 2011.

[23] Park, C.Y. (2007). Maintaining Korean as a heritage language, Ph.D. dissertation, Arizona State University, AAT 3287994, http://proquest.umi.com, accessed on April 12, 2011.

[24] Ramirez, D.B. (2007). Language attrition and language maintenance: The case of Colombian immigrants in New York State, Ph.D., State University of New York at Albany, AAT 3270285, http://proquest.umi.com, accessed on April 16, 2011.

[25] Richards, J.C., and R. Schmidt, (2002). Longman Dictionary of Language Teaching and Applied Linguistics (3rd Edition), Person Education Limited.

[26] Saxena, M. (1995). A sociolinguistic study of Panjabi Hindus in Southall: Language maintenance and shift, D.Phil. dissertation, The University of York (United Kingdom), AAT C505148, http://proquest.umi.com, accessed on April 9, 2011.

[27] Sofu, H. (2009). Language shift or maintenance within three generations: examples from three Turkish-Arabic-speaking families, International Journal of Multilingualism, Vol. 6, No. 3, August 2009, pp. 246_257

[28] Somerholter, K. E. (1999). Language contact and shift in the Soviet German speech community, Ph.D. dissertation, The University of Texas at Austin, AAT 9947394, http://proquest.umi.com, accessed on March 1, 2011.

[29] Stoessel, S.(1998) The investigation of social networks as a factor in language maintenance and shift, Ph.D. dissertation, Boston University, AAT 9825415, http://proquest.umi.com, accessed on January 23, 2011.

[30] Subhan, S. (2007). Heritage language maintenance among Bangladeshi immigrants in Toronto, Ed.D. dissertation, Northern Arizona University, 2007 , AAT 3296090, http://proquest.umi.com, accessed on January 20, 2011.

[31] Sun, L. (2000). First language maintenance in recent Chinese immigrant families , Ed. D. dissertation, Texas Tech University, 233 pages; AAT 9963539, http://proquest.umi.com, accessed on December23, 2009.

[32] Thiollet, H. (2007). Refugees and migrants from Eritrea to the Arab world: the case of Sudan, Yemen, and Saudi Arabia 1991 2007. Paper prepared for the migration and refugee movements in the middle east and north Africa, the forced migration and refugee studies program, the American university in cairo, Egypt October $23-25,2007$, http://www.aucegypt.edu/GAPP/cmrs/Documents/HeleneThiollet.pdf, accessed on February 12, 2011.

[33] Van Aswegen, J.G. (2008). Language maintenance and shift in Ethiopia: The case of Maale, M.A., University of South Africa (South Africa), AAT 0669289,http://proquest.umi.com, accessed on March 22, 2009.

[34] Veltman, C. (1983). Language Shift in the United States. Berlin: Mouton.

[35] Veltman, C. (1991). Theory and method in the study of language shift. In J.R. Dow (Ed.), Language and Ethnicity: Focus schrift in honour of Joshua, A. Fishman, Philadelphia: John Benjamins Publishing Company, pp. 145- 167.

[36] Venditti, R.L.(2003).Women and ethnic language maintenance: A study of Italian immigrant family triads in Sainte-Leonard, Montreal, M.P.P.A., Concordia University (Canada), 2003 , AAT MQ83831, http://proquest.umi.com, accessed on October 21, 2010.

[37] Weinreich, U. (1964). Language in Contact. The Hague: Mouton.

[38] Xie, M. (2010). First language maintenance and attrition among young Chinese adult immigrants: A multi-case study, Ed. D.dissertation, University of Alberta (Canada), AAT NR60569, http://proquest.umi.com, accessed on March6, 2011.

[39] Yakoubu, N.M. (1994). Sociolinguistic inquiry into language maintenance and language shift among sub-Saharan Africans in the United States of America: An example in western Pennsylvania, Ph.D. dissertation, Indiana University of Pennsylvania, AAT 9412974, http://proquest.umi.com, accessed on April 16, 2011.

[40] Zhang, D. (2005). Home language maintenance and acculturation among second-generation Chinese children, Ph.D. dissertation, University of Pennsylvania, AAT 3165775, http://proquest.umi.com, accessed on February 1, 2011.

[41] Zhang, D. (2010). Language Maintenance and Language Shift Among Chinese Immigrant Parents and Their SecondGeneration Children in the U.S., Bilingual Research Journal, 33: pp. 42-60. 


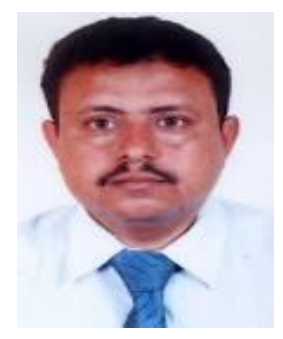

Hussein Ali Habtoor is an assistant professor of applied linguistics. He earned his $\mathrm{PhD}$ in Linguistics in 2005 from Aligarh Muslim University, India. He is affiliated to Aden University, Yemen. He worked as an assistant professor of English language at King Saud University, Riyadh, KSA and currently he is working at Najran University, KSA where he has coordinated the Department of English at the Arts Faculty for two years. He has been teaching English to Arab Learners in the above mentioned institutions for several years. His areas of interest include reading research, language teaching, language and culture, sociolinguistics and translation. 